\title{
The Roles of Emotional Intelligence and Spiritual Intelligence at the Workplace
}

\author{
Susan Tee Suan Chin, R.N. Anantharaman and David Yoon Kin Tong \\ Faculty of Business and Law, Multimedia University, Melaka, Malaysia
}

\begin{abstract}
The workplace environment keeps on changing, indicating its dynamic nature as well as unpredictability. The workforce is now more diverse, not only in terms of age but also of nationality. Globalization has made the world boundaryless and people are now mobile. Organizations require its employees to be more committed as well as to have a better cohesive working interrelationship. Emotional Intelligence is the ability to sense, understand and effectively apply the power and acumen of emotions as a source of human energy, information, connection and influence. Spiritual intelligence is the set of abilities that individuals use to apply, manifest and embody spiritual resources, values and qualities in ways that enhance their daily functioning and well-being. With both these intelligences happening in the workplace, the environment will be more conducive. A better working environment relates to a higher level of productivity.
\end{abstract}

Keywords : Emotional Intelligence, Spiritual Intelligence, Interpersonal relationships

\section{Introduction}

The nature of work is constantly changing (Biberman and Whitty 1997). This is evident in the kinds of jobs that employees used to be engaged for. Traditional concept of lifetime employment has also changed. Employees of the future need to demonstrate to the organizations that they can add value to the organization (Harari 1993). Organizations from not only Japan but also the United States of America have started to show an interest in spiritual values (Brandt 1996, Galen 1996, Labbs 1995, Vicek 1992). Organizational soul and workforce spirit have often been overlooked and ignored by many (Biberman and Whitty 1997). Work life reaches and touches into the very soul and spirit of all employees at work. Those at work are constantly seeking ways to improve themselves and a sense of contribution to their work life. Workplace unity creates a stronger organization, one that can withstand the uncertainties in this dynamic business environment. This form of spirit requires not only the spiritual intelligence but also emotional intelligence. Emotional Intelligence has garnered attention from psychologist, educators, leadership theorists and business leaders (Burbach, et. al 2003). Due to globalization, workplaces have a diversity of employees. As with diversity, collaboration, co-operation and teamwork have become increasingly important issues for management to handle. The current prime minister of Malaysia Datuk Seri Najib Tun Abdul Razak has unveiled the new economic model which will act as the driver for the economy. The new economic model requires the best of human capital (The Star 2009). The workplace constitutes people. With people, there needs to be relationships. Employees with good interpersonal skills should be seen as a valuable asset. The

Copyright (C) 2011 Susan Tee Suan Chin, R.N. Anantharaman and David Yoon Kin Tong. This is an open access article distributed under the Creative Commons Attribution License unported 3.0, which permits unrestricted use, distribution, and reproduction in any medium, provided that original work is properly cited. Contact author: Susan Tee Suan Chin e-maill: tschin@mmu.edu.my 
purpose of this paper is to highlight the importance of spiritual intelligence as well as emotional intelligence at the workplace especially for developing countries like Malaysia.

\section{Literature Review}

\section{Emotional Intelligence}

John Mayer and Peter Salovey (1997) have defined emotional intelligence as the ability to perceive emotions, to access and generate emotions so as to assist thought, to understand emotions and emotional knowledge and to effectively regulate emotions so as to promote emotional and intellectual growth." Emotional intelligence is the ability to sense, understand and effectively apply the power and acumen of emotions as a source of human energy, information, connection and influence (Cooper and Sawaf 1998). Emotional Intelligence may be defined as the ability to perceive, understand, integrate and manage one's own and other people's feelings and emotions, and to act upon them in a reflective and rational manner (Chartered Management Institute 2004). When applied to the workplace, emotional intelligence involves the capacity to effectively perceive, express, understand and manage emotions in a professional and effective manner at work (Palmer and Stough 2001). According to the Genos EI (previously named as Swinburne University Emotional Intelligence Unit), there are five key emotional competencies which are applicable to the workplace situation:-

i) Emotional Recognition and Expression refers to the ability to identify one's own feelings and emotional states and the ability to express those inner feelings to others.

ii) Understanding Others Emotions - refers to the ability to identify and understand the emotions of others and those that manifest in response to workplace environments and staff meetings. iii) Emotions Direct Cognition - refers to the extent to which emotions and emotional knowledge are incorporated in decisionmaking and or problem solving situations

iv) Emotional Management - refers to the ability to manage positive and negative emotions both within oneself and others

v) Emotional Control - refers to the ability to effectively control strong emotional states experienced at work such as anger, stress, anxiety and frustration.

Mayer and Salovey (1997) have conceptualized emotional intelligence as a set of mental abilities concerned with emotions and the processing of emotional information. Mayer and Salovey's ability model of emotional intelligence comprises of four conceptually related abilities arranged hierarchically from the more basic psychologically complex, including:

(1) The ability to perceive emotions;

(2) The ability to utilize emotion to facilitate reasoning;

(3) The capacity to understand the meaning of emotions and the information they convey; and

(4) The ability to effectively regulate and manage emotion

The measures of emotional intelligence are expected to

(a) show a positive manifold of correlations amongst the subscales designed to assess the four major areas;

(b) show a consistent factor structure that comprises of a general factor of emotional intelligence and four correlated primary factors;

(c) show age related differences that reflect the developmental perspective of the model 
Emotions are expected to be assimilated into a thought so that it will be evaluated against other emotions, sensations or thoughts. Cultural and environmental factors influence the thoughts of a person. These factors would include the place where the individual lives in.

\section{Spiritual Intelligence}

Emmons (2000) have defined spiritual intelligence as "the adaptive use of spiritual information to facilitate everyday problem solving and goal attainment". He had suggested five components of spiritual intelligence:

1. The capacity to transcend the physical and material.

2. The ability to experience heightened states of consciousness.

3. The ability to sanctify everyday experience.

4. The ability to utilize spiritual resources to solve problems.

\section{The capacity to be virtuous.}

Noble $(2000 ; 2001)$ has identified spiritual intelligence as an innate human potential and agreed with Emmons' (2000) core abilities and added two other elements:

1. The conscious recognition that physical reality is embedded within a larger, multidimensional reality with which people interact, consciously and unconsciously, on a moment to moment basis.

2. The conscious pursuit of psychological health, not only for themselves but also for the sake of the global community.

According to Wigglesworth (2002), "Spiritual intelligence is the ability of individuals to behave with wisdom and compassion while maintaining inner and outer peace, regardless of the situation." There are four hierarchies in terms of the human intelligence. The hierarchies are depicted in a pyramid shape which shows the sequence of development. As babies, the first step is to control their bodies, this is Physical Intelligence. The next development is the linguistic and cognitive abilities, these are known as Intelligence Quotient. The individual will then develop the Emotional Intelligence before gaining the Spiritual Intelligence.

According to Wigglesworth (2002), the emotional abilities come earlier than spiritual abilities. Both of these abilities are related to each other. They strengthen each others' abilities. As reported in Times in India (2010), Spiritual intelligence increases an individual's capacity to understand others at a higher level. Spiritual understanding allows an individual to discern both the 'true cause' of behaviour without judgment, and serve the 'true needs' of others until they themselves learn to meet their own needs. This capacity is developed by first learning to free oneself from attachment and neediness and being able to meet our own inner needs. Attachment and neediness are the opposite of being spiritually intelligent. Being able to recognize, understand and respond to the emotions of others requires a level of emotional literacy that can only be developed by learning to recognize one's own feelings and emotions (self-awareness again). This falls squarely in the arena of emotional intelligence.

Vaughn (2002) described "Spiritual intelligence as being concerned with the inner life of mind and spirit and its relationship to being in the world. According to him, Spiritual intelligence implied a capacity for a deep understanding of existential questions and insight into multiple levels of consciousness. Spiritual intelligence also implies awareness of spirit as the ground of being or as the creative life force of evolution. If the evolution of life from stardust to mineral, vegetable, animal, and human existence implied some form of intelligence rather than being a purely 
random process, it might be called spiritual. Spiritual intelligence emerges as consciousness evolves into an everdeepening awareness of matter, life, body, mind, soul, and spirit. Spiritual intelligence, then, is more than individual mental ability. It appears to connect the personal to the transpersonal and the self to spirit. Spiritual intelligence goes beyond conventional psychological development. In addition to self-awareness, it implies awareness of our relationship to the transcendent, to each other, to the earth and all beings. Working as a psychotherapist, his impression is that spiritual intelligence opens the heart, illuminates the mind, and inspires the soul, connecting the individual human psyche to the underlying ground of being. Spiritual intelligence can be developed with practice and can help a person distinguish reality from illusion. It may be expressed in and culture as love, wisdom, and service."

According to George (2006), spiritual intelligence is necessary for a number of factors. Spiritual intelligence assists in finding the deepest and most inner resource from an individual from which the capacity to care, the power to tolerate and adapt is obtained. It also aids in the development of a clear and stable sense of identity among individuals especially in the context of workplace relationships. With this in mind, work would be more meaningful for the employees. Spiritual intelligence helps in identifying and aligning personal values of the employee with a clear sense of purpose. Employees would be able to demonstrate a high level of integrity. Employees would also be able to understand and influence the "true cause".

Zohar and Marshall (2000) have defined Spiritual Intelligence as the intelligence in which individuals address and solve problems of meaning and value. It also describes the intelligence that individuals can place their actions and their lives in a wider, richer, meaning-giving context. According to Zohar and Marshall (2000), spiritual intelligence allows individuals to assess which is a more meaningful course of action or life-path. According to Amram (2007), spiritual intelligence is the set of abilities that individuals use to apply, manifest and embody spiritual resources, values and qualities in ways that enhances their daily functioning and well-being.

Amram and Dryer (2007) have developed their construct of Spiritual Intelligence and it contains five broad domains. They are; Consciousness, Grace, Meaning, Transcendence and Truth. Consciousness reflects the ability to raise or shift consciousness, to tap intuition and to synthesize multiple view points in ways that will enhance daily functioning and wellbeing. Grace reflects the love for life, drawing on the inspiration, beauty and joy inherent in each present moment to enhance the functioning and well-being. Grace can be divided into six subscales; Beauty, Discernment, Freedom, Gratitude, Immanence and Joy. Beauty in the context of the workplace situation, refers to the appreciation of the beauty from the working environment and also the nature of the duties and responsibilities. Discernment refers to the alignment of the actions and the values of the individual. Freedom refers to the actions of the individuals against the rules and regulations. Gratitude refers to the thankfulness of the individual for the things that happen to come their way. Immanence refers to the simple things in life and also nature. Joy refers to the choices available to the individual and also their ability. As for Meaning, another main domain for Spiritual Intelligence, it reflects the ability to experience meaning, link activities and experiences to values and construct interpretations in ways that enhance functioning and wellbeing in the face of pain and suffering. Meaning can be divided into two subscales; Purpose and Service. Purpose refers to the objectives of the individuals at work, as to whether they see work as advancement. Service reflects the expressions of individuals at the workplace, whether work is seen as an expression of love or chore. Transcendence refers to the 
ability to align with the sacred and transcend the egoistic self with the sense of relatedness and holism in ways that enhances functioning and wellbeing. Transcendence can be divided into five subscales; Higherself, Holism, Practice, Relatedness and Sacredness.

\section{Nature of the Workplace Environment}

The actions of the employees affect the success of the business in whatever the nature of the industry (Wright 2008). Wright (2008) has illustrated that whatever the employees have and feel, the organization will benefit in terms of customer satisfaction, operational outcomes and financial outcomes. Each employee has different levels of skills, abilities and competencies. They have different levels of experiences and background. These could be due to their different educational background and also the previous working experiences. Based on these differences, they will display different sets of motivation, commitment and engagement. These will be seen in their behaviour which could be positive or negative. Employees who are happy will show positive attitudes. These behaviours have been termed as organizational citizenship behaviour. They include the level of contribution and support by the employee to the organisation. According to Wright (2008), if employees are happy or satisfied, they will perform well in their job. Customers will be satisfied with the service received. This will result in a better customer relationship which translates into higher revenue and profits for the organization.

Employees are governed by their cognitive abilities. This is seen in terms of their level of skill, abilities and competencies. The higher their knowledge level, the higher their level of skills, abilities and competencies raises as well. Knowledge is an important resource in the very competitive business environment (Choe 2004). Learning prioritizes the creation and acquisition of new knowledge. It emphasizes the roles of the people in the creation and utilization of the knowledge and information.

According to the American Society for Training and Development (ASTD) (2005), good interpersonal relationships in the organization improve the climate. A better organizational climate enables the top management to predict the performance of the organization. In a study conducted by Schumacher (2005), based on 34 supply managers and 102 suppliers, it was found that Emotional Intelligence does impact the performance of the supply managers. It was found that successful store managers who were good in managing people's feelings, handling stress and other emotional intelligence competencies achieved higher net profits.

Employees' feelings are represented in terms of the level of motivation, commitment and engagement. According to a study conducted by the University of Montreal (Financial Post 2007), employees from the manufacturing sector face many challenges in their working life. This has caused them to suffer from poor health. Furthermore, during the recent financial crisis many organizations had to take serious cost cutting measures which include the need to retrench employees. Employees feel very insecure as they feel threatened financially, if they are the sole bread winner for their family.

\section{Roles Played}

Both Emotional Intelligence and Spiritual Intelligence refers to the inner most feelings or souls of the employees. It allows employees to be motivated intrinsically rather than extrinsically. According to Katz and Kahn (1978), in terms of individual job performance, three elements can be used, which are

- Joining and staying with the organization.

- Dependably meeting or exceeding standards of performance prescribed by organizational roles (in-role performance). 
- Innovatively and spontaneously going beyond prescribed roles to perform such actions as co-operating with others, protecting the organization from harm, offering suggestions for improvement and representing the organization favourably to outsiders (extra-role performance).

Organizational Citizenship Behaviour (OCB) has been defined as the extra-role, discretionary behaviour that helps other members in the organization to perform their jobs. OCB also includes showing support and conscientiousness towards the organization (Smith et al, 1983; Bateman and Organ 1983; Borman and Motowidlo 1993). According to Podsakoff et al (1990) OCB has five elements that measures conscientiousness, sportsmanship, civic virtue, courtesy and altruism.

- Conscientiousness - punctuality in attendance, use of work time and adherence to rules. It also refers to the trait of being painstaking and careful, or the quality of acting according to the dictates of one's conscience. It includes such elements as self-discipline, carefulness, thoroughness, organization, deliberation (the tendency to think carefully before acting), and need for achievement. It is an aspect of what was traditionally called character. Conscientiousness is related to emotional intelligence and impulse control.

- Altruism - helping others who have been absent or are behind in their work (any voluntary action that helps another person out at work). It is often referred to as the willful sacrifice of one's own interests or well-being for the sake of something that is non-self. It is also often defined as being the selfless concern for the welfare of others.

- Sportsmanship - putting up with minor inconveniences, or not always finding fault with the organization

- Courtesy - consulting people who may be affected by a decision or at the very least informing other people in advance of such actions

- Civic virtue - keeping up with developments happening in the organization (being constructively involved in the political process of the organization).

The organization will benefit from this. They will have a lower rate of turnover. Attendance would improve. As such, productivity increases. Once productivity increases, the revenue and profits increases as well. Both Emotional Intelligence and Spiritual Intelligence have an impact on work success. They improve work performance, improve relations among co-workers, increase level of job satisfaction and decrease turnover propensity (Frew, 1974; Alexander et al 1993).

According to Cacioppe (1999), development in the organization leads to the emergence of team spirit. It occurs when the level of self awareness in an individual increases to a higher level of consciousness in them. At each stage of the development of self awareness, the individual goes through a process of differentiation and integration. Development is a process of building higher, deeper and more complex levels of union.

The current focus on organizational transformation which involves radical changes in how individuals in the organization perceive, think and behave at the workplace. This is important as the environment is very dynamic. It has become unpredictable. The magnitudes of change that occur are not only large but also alter the foundation and the mental framework of organizations (Cacioppe 1999). Evolution and development are integral to this process of change. This leads to a higher level of creativity and spirituality.

According to Burack (1998), spiritual growth and advancement of individuals involves mental growth. Problem solving and learning will be the main vehicles of the individual's 
development. Spiritual growth reflects the gratification of the needs of the individual especially in terms of the "belonging needs." It also relates to the higher order of needs, this is as per Maslow's hierarchy of needs which includes the self actualization needs. This relates to the workplace setting conditions for example, the job responsibilities. Spirituality in the workplace is reinforced through the leaders in the organization. This is seen in the organization's culture, policies and work design.

According to Fairholm (1996), work has become the main feature of many people. It has also become the main issue in the society. On the average, an individual who is working in the office works about 10 hours. The workplace has become a place where individuals or the employees find their sense of full meaning. As per Maslow's hierarchy of needs, the top most level is the selfactualization needs. Employees achieve that level after they have gone through the lower level needs. The spirit at work becomes the guiding principles of wholeness, relationships, inner wisdom and inner authority. According to Kantrowitz (1994), individuals are anxious to know their meaning of life. They would like to relate their spiritual selves with their professional lives.

\section{Conclusion}

As suggested by Wright (2008), the skills, abilities and competencies coupled with the level of motivation, commitment and engagement act as drivers in terms of the employees' actions. Their task and discretionary behaviour improves. Both Emotional Intelligence and Spiritual Intelligence touch the "nerve" of the employees. It "makes" them to go beyond the normal actions. Emotional intelligence, when applied to the workplace, involves the capacity to effectively perceive, express, understand and manage emotions in a professional and effective manner at work (Palmer and Stough 2001). Spiritual intelligence is the set of abilities that individuals use to apply, manifest and embody spiritual resources, values and qualities in ways that enhances their daily functioning and well-being (Amram 2007). With both these intelligences in play, the employee would be an asset to the organization. Both Spiritual Intelligence and Emotional Intelligence complement each other. The working environment has become a main feature in many people's lives especially for those who are working.

As argued by Wright (2008), employees will display behaviours based on their different characteristics. Their characteristics depend largely upon their level of cognitive and noncognitive abilities. Cognitive abilities refer to their level of education, skill and experience. Non-cognitive abilities refer to the levels of Emotional Intelligence and Spiritual Intelligence. Both these abilities complement each other. Their complementariness will result in a better workforce for the organization. They will display better levels of teamwork, co-operation and inter-active skills. A united workforce will strengthen the organization and their cohesiveness will increase the level of productivity in the organization. Customers will be happy. They will want to patronize the organization more often. Sales will increase. Profits and market growth rise as well. Organization would benefit from both the Emotional and Spiritual Intelligences.

\section{References}

Alexander, C. N., Swanson, G. C., Rainforth, M.V., Carlisle, T. W., Todd, C.C. \& Oates, R. M. (1993). "Effects of Transcendental Meditation Program on Stress Reduction, Health and Employee Development: A Prospective Study in Two Occupational Settings," Anxiety, Stress and Coping: An International Journal. Vol. 6, pp 245-262

Amram, Y. (2007). "The Seven Dimensions of Spiritual Intelligence: An Ecumenical Grounded Theory," Presented at the 115th Annual Conference of the American 
Psychological Association, San Francisco, CA. August 17-20, 2007

Amram, Y. \& Dryer, C. (2007). 'The Development and Preliminary Validation of the Integrated Spiritual Intelligence Scale (ISIS),' Institute of Transpersonal Psychology, Palo Alto, CA. Working Paper

ASTD (2005). 'Organizational Climate Helps Predict Performance,' June 2005

Bateman, T. S. \& Organ, D. W. (1983). "Job Satisfaction and the Good Soldier: The Relationship between Affect and Employee Citizenship," Academy of Management Journal, No. 26, Pp 587-595

Biberman, J. \& Whitty, M. (1997). "A Postmodern Spiritual Future for Work," Journal of Orgnizational Change Management. Vol. 10, No. 2. 1997, pp 130-138

Borman, W. C. \& Motowidlo, S. J. (1993). 'Expanding the Criterion Domain to Include Elements of Contextual Performance,' Schmitt, N. and Borman, W.C. (Eds). Personnel Selection in Organisations. Pages 71-98 San Francisco, CA: Jossey-Bass.

Brandt, R. (1996). "Corporate Pioneers Explore Spirituality: Peace," HR Magazine, Vol. 41. No. 4. April, pp 82-87

Burack, E. H. (1998). 'Spirituality at the Workplace,' Journal of Organisational Change Management. Vol. 12 No. 4, pp 280-292

Burbach, M. E., Barbuto, J. E. Jr \& Wheller, D.W. (2003). 'Linking Am Ability Model of Emotional Intelligence to Transformational Leadership Behaviours,' http://cpbacourses.crieghton.edu/MAM/200 3/papers/burbach.doc

Cacioppe, R. (2000). "Creating Spirit At Work: Re-Visioning Organization Development And Leadership - Part ll," Leadership and Organization Development Journal 21/2 pp 110-119

Chartered Management Institute (2004). 'Emotional Intelligence,' http://www.managers.org.uk/content_3.asp $x$ ?id=3:876\&id=3:431\&id=3:44 (Accessed on 31 December 2004).

Choe, J.-M. (2004). "The Consideration of Cultural Differences in the Design of Information Systems", Information and Management, Vol. 41 No.5, pp 669-88

Cooper, R. \& Sawaf, A. (1998). 'Executive EQ: Emotional Intelligence in Business,' London: Orion.

http://competencyandei.com/Definition-ofemotional-intelligence-

Emmons, R.A. (2000). "Is Spirituality an Intelligence? Motivation, Cognition and the Psychology of Ultimate Concern," The International Journal for the Psychology of Religion. 10:27-34.

Fairholm, G.W. (1996). "Spiritual Leadership: Fulfilling Whole-Self Needs at Work," Leadership and Organization Development Journal. Vol 17 No. 5. pp 11-17.

Financial Post (2007). "Study Ranks Most Stressful Jobs," Thursday 4 October 2007 [online] Available :

http://www.financialpost.com/story.html?id =dc7da623-c273-48c0-99f1-

ff9daad70bf5\&k=96830 [Access on 16

October 2008]

Frew, D.R. (1974). "Transcendental Meditation and Productivity," Academy of Management Journal. Vol. 17. Pp 362-368

Galen, M. (1995). 'Companies Hit the Road Less Traveled,' Business Week, No. 3427, 5 June pp. 82-84

George, M. (2006). "Practical Applications of Spiritual Intelligence in the Workplace," Human Resource Management International Digest. Vol. 14, No.5, 2006

Harari, 0. (1993). "Back to the Future of Work," Management Review. Vol. 82 No. 9 September, pp 33-35 
9 Journal of Human Resources Management Research

Kantrowitz, B. (1994). "In Search of the Sacred," Newsweek. 28 November. Pp 53-55

Katz, D. \& R. Kahn (1978). 'The Social Psychology of Organisations,' New York: Wiley and Sons.

Labbs, J.J. (1995). 'Balancing Spirituality at Work,' Personnel Journal, Vol 74. No. 9. pp 6076

Mayer, J. D. \& Salovey, P. (1997). 'What is Emotional Intelligence?,' In P. Salovey and D. Sluyter (Eds.), Emotional development and emotional intelligence (pp3-31). New York:Basic Books.

Noble, K.D. (2000). 'Spiritual Intelligence: A New Frame of Mind,' Advanced Development, 9, 1-29

Noble, K.D. (2001). 'Riding the Windhorse: Spiritual Intelligence and the Growth of the Self,' Cresskill, NJ: Hampton Press

Palmer, B. \& Stough, C. (2001). 'Swinburne University Emotional Intelligence Test. Interim Technical Manual,' Organistional Psychology Research Unit

Podsakoff, P. M., Mackenzie, S.B., Moorman, R.H. \& Fetter, R. (1990). Transformational Leaders Behaviour and their Effects on Followers' Trust in Leader, Satisfaction and Organizational Citizenship Behaviours. The Leadership Quarterly 1, 107-142

Schumacher, L.A. (2005). 'The Relationship Between Supply Managers Emotional Intelligence and their Performance,' Phd Dissertation. Bowling Green State University

Smith, C. A., Organ, D.W. \& Near, J. P. (1983). "Organizational Citizenship Behaviour: Its Nature and Antecedents," Journal of Applied Psychology, No. 68, Pp 653-663

The Star (2009). "Najib Outlines Three Core Strategies to Boost Growth," (Available online at url address: http://thestar.com.my/news/story.asp?file= /2009/10/24/budget2010/4971605\&sec=b udget2010). Accessed on 24 October 2009

The Times of India (2010). "What is Spiritual Intelligence?," Available online at url address : http://timesofindia.indiatimes.com/lifestyle/spirituality/science-of-spirituality /What-is-spiritual-intelligence/articleshow/5343214.cms. Accessed on 17 December 2010

Vaughan, F. (2002). "What is Spiritual Intelligence?," Journal of Humanistic Psychology, Vol 42, No. 2. Spring 2002, 16-33 Sage Publications

Vicek, D. J. (1992). 'The Domino Effect,' Small Business Reports, Vol. 17, No. 9, Winter pp2125

Wigglesworth, C.S.G. (2002). "Spiritual Intelligence and Why it Matters," (Available online at http://www.consciouspursuits.com/Articles /SIWhyItMatters.pdf). (Accessed on 16 December 2010).

Wright (2008). 'Human Strategy and Performance,' http://moss07.shrm.org/about/foundation/ products/Documents/HR\%20Strategy\%20E PG-\%20Final\%200nline.pdf

Zohar, D. \& Marshall, I. (2000). 'SQ : Connecting with our Spiritual Intelligenc,' New York. Bloombury. 